\title{
REGENERACIONISTAS, GUBERNISTAS, DISIDENTES Y REFORMISTAS COMBATEN EN EL RADICALISMO. SANTA FE, 1910-1916*
}

Bernardo Carrizo

bcarrizo@fhuc.unl.edu.ar /

Profesor en Historia. Docente ordinario e investigador de la Facultad de Humanidades y Ciencias de la Universidad Nacional del Litoral (FHUC-UNL). Santa Fe. Argentina.

\footnotetext{
* Se exponen aquí algunas ideas debatidas en el proyecto de investigación "Culturas políticas y discursividad. Santa Fe, 1912-2001", que se lleva adelante en la Facultad de Humanidades y Ciencias (UNL), en el marco de la Programación CAI+D 2016 de la Secretaría de Ciencia y Técnica.
} 


\section{RESUMEN}

Este artículo propone analizar la experiencia política de la Unión Cívica Radical de Santa Fe (UCRSF) en la provincia homónima, en el lapso que media aproximadamente entre 1910 y 1916. La enriquecedora variación de escalas de análisis —-lo local, lo provincial y lo nacional, que a su vez conforman diversos territorios de la política- permite la comprensión de fenómenos que se centran en una indagación sobre la Unión Cívica Radical (UCR) como partido nacional. Pero detener la mirada en un espacio provincial en articulación con las culturas políticas, permite analizar a «los radicalismos» que protagonizaron los primeros tramos de la democratización, y que aspiraban a la regeneración de la política. En este marco, una hipótesis que ordena el trabajo se orienta hacia los lazos que unieron y, al mismo tiempo, tensionaron a los radicales hasta el extremo de que el adversario, a través del discurso político, era presentado y definido como ilegítimo. $Y$ en esta clave, se instala la pregunta sobre cuál ha sido la impronta que esa idea de ilegitimidad respecto del adversario ha dejado en la cultura política argentina.

\section{PALABRAS CLAVE}

$>$ radicalismos

$>$ regeneracionismo

$>$ discurso político

$>$ cultura política 


\section{ABSTRACT}

This article tries to analyze the political experience of Unión Cívica Radical of Santa Fe (UCRSF) at the homonymous province, during the approximate lapse between 1910 and 1916. The enriching shift of analysis scales - the local, the provincial and the national, which at the same time make various territories of politics - allows the understanding of events focused on a central inquiry about the Unión Cívica Radical (UCR) as a national party. Concentrating the look on a provincial space articulated with political cultures, allows to analyze «the radicalismos» that starred the first stretches of democracy, and that aspired to the regeneration of politics. In this frame, one hypothesis that guides this work is oriented towards the links that joined and, at the same time, stressed the radicals until the point that the opponent through the political speech was presented and defined as illegitimate. And in this key, the question about which has been the imprint that the idea of illegitimacy with respect of the opponent has left in Argentinian political culture was installed.

\section{KEYWORDS}

$>$ radicalismos

$>$ regeneracionismo

$>$ political speech

$>$ political culture 


\section{RADICALISIMO Y RADICALISMOS}

El abordaje del radicalismo en sus diferentes facetas —organización partidaria, identidad política, partido de gobierno, miembro de la oposición- abreva en diversos registros, tanto los relatos de testigos y militantes que escribieron la historia del mismo como lo producido por cientistas sociales. En el plano historiográfico, el presente artículo es tributario de las nuevas reflexiones que han enriquecido a la historia política en las últimas décadas, cuyas contribuciones tematizan la política y lo político, generándose una ampliación de este último pero en intensa articulación con la primera. Diversas investigaciones y producciones académicas han expuesto un entramado de problemáticas -escenarios parlamentarios y electorales, el lugar de la violencia política, la tensiones entre historia militante y memoria colectiva, actores sociales y políticos, intelectuales y cultura política, partidos políticos y bloques de poder, por citar solo algunas-en donde la política —instituciones y normas vinculadas al poder y su ejercicio- y lo político -lo que anima a los sujetos a desplegar sus prácticas y que guarda relación con los conflictos por la hegemonía- (Rosanvallon, 2003) atraviesan a la democracia como experiencia histórica — ella misma sistemáticamente interpelada como fenómeno social en cotejo permanente con lo que idealmente supone- - y donde el vínculo entre Estado nacional y Estados provinciales — que conduce al aspecto federal del fenómeno del poder en Argentina- expone diversas escalas en el tratamiento de las cuestiones que la rodean.

Nos proponemos analizar el radicalismo en un espacio subnacional, la provincia de Santa Fe, en el lapso que media aproximadamente entre 1910 y 1916 , período enmarcado por años que poseen una carga conmemorativa al calor de sendos centenarios. La enriquecedora variación de escalas de análisis -lo local, lo provincial y lo nacional, que a su vez conforman diversos territorios de la política- permite la comprensión de fenómenos que la perspectiva nacional colocaba en un plano de inicial homogeneidad.

En la tensión que se genera, entre novedosos instrumentos prescriptivos propuestos por la reforma política de 1912 y prácticas asentadas en un mundo conservador que se muestra resistente, se instala la experiencia de la temprana democracia electoral santafesina. El vínculo entre la UCRSF (Unión Cívica Radical de Santa Fe) y la UCR (Unión Cívica Radical) se presenta como una manera de colocar 
en diálogo no sólo la relación nación-provincia en clave electoral, sino también la articulación entre dos organizaciones partidarias aglutinadas por una misma marca, un mismo sello y ciertos «objetos temáticos intocables» (Angenot, 2010).

En este marco, destacamos dos dimensiones que acompañan las interpretaciones que recorren estas páginas. Por un lado, como ha señalado Darío Macor, la necesaria consideración de los espacios provinciales:

Como territorios de producción de lo político, es decir, donde se generan procesos que ayudan a explicar no solo el devenir de los acontecimientos —locales y nacionales-, sino también importantes rasgos de la identidad política de los sujetos colectivos que se constituyen en ese devenir y la funcionalidad de estos sujetos en relación al poder (Macor e Iglesias, 1997:12-13).

Por otro lado, el terreno de la cultura política que proporciona un abanico de matices para comprender la complejidad de los comportamientos e indagar la dinámica de actores e instituciones. El concepto de referencia ha sido relevante para otorgar nuevos aires a la historia, no obstante, guarda diversos significados y apuesta a distintos componentes «que van desde los valores y significados que subyacen a la práctica política, pasando por los principios y representaciones simbólicas de la realidad social» (Cabrera, 2010:79). Coincidimos con Serge Berstein en la delimitación del concepto cultura política pues destaca dos elementos: la importancia del papel de las representaciones que la hace algo diferente de una ideología o de un conjunto de tradiciones, y «el carácter plural de las culturas políticas en un momento dado de la historia y en un país determinado» (1999:390).

El terreno de las culturas políticas resulta sumamente enriquecedor para el análisis de algunos aspectos de la historia argentina. En esta clave, un desafío radica en comprender los motivos que conducen a asumir ciertos comportamientos políticos, a optar por unos principios de legitimidad o por un sentido del orden por sobre otros. Sólo como forma de exponer algunos de los ingredientes que son constitutivos de las culturas políticas, es posible mencionar: una visión del mundo, una lectura común y normativa del pasado que pone en relevancia ciertos hechos como gesta, una definición sobre el tipo de organización política deseable, un discurso significativo cuyos componentes (palabras clave, consignas, imágenes) dan cuenta, junto a ciertos ritos y símbolos, de la ocupación del espacio público. 
En este marco, una de las hipótesis que ordena el presente trabajo se orienta hacia los lazos que unieron y, al mismo tiempo, tensionaron a los radicales, hasta el extremo que el adversario - tanto radical como de otra pertenencia partidariaera visto como un adversario ilegítimo. En esta clave nos preguntamos cuál ha sido la impronta que esa idea de ilegitimidad respecto del adversario ha dejado en la cultura política argentina.

\section{LA CULTURA POLÍTICA EN LA TRAMA FACCIOSA SANTAFESINA}

La política es un universo de actores, prácticas, ideas, normas, representaciones que dan lugar a una cultura política que cristaliza, por esos años, en un conjunto de prácticas que tiene en los notables a sus principales dirigentes aunque cada vez más involucrados en organizaciones partidarias que se expanden institucionalmente sobre diversos territorios. $Y$ ese mundo de notables de provincia era también el de una democratización —que tuvo en la reforma política de 1912 su manifestación más contundente- puesta en tensión en su devenir por las acciones y las ideas de unos actores que ejecutaban nuevas reglas con viejas prácticas, en un mapa electoral que se ampliaba de a poco, y cuyo resultado más evidente fue consolidar al radicalismo como uno de sus principales protagonistas.

En la coyuntura 1910-1916 el distrito santafesino se destacó del conjunto nacional por el protagonismo que asumió la UCRSF. En el escenario definido por la reforma política de 1912, el análisis de la experiencia del radicalismo santafesino hace que nos propongamos indagar las condiciones que hicieron de la disidencia, devenida en una dinámica facciosa inherente a las formas de practicar la política, una acompañante permanente del radicalismo. El interrogante invita al análisis del radicalismo hacia fuera y hacia dentro de la UCRSF durante los años de la gestión que encabezaron, luego del triunfo electoral de 1912, Manuel Menchaca y Ricardo Caballero, primera experiencia en la historia provincial y nacional. Pero también amerita colocar sobre el tapete los vínculos que la UCRSF mantuvo con la UCR en el pasaje de partido de oposición - con un pasado revolucionario- a partido de gobierno. En los límites de estos planteos, los radicales esgrimieron 
un pasado reciente en el que la violencia revolucionaria había dado lugar a la definición de una identidad política que se propuso, en coincidencia con otras voces, la regeneración de la política y sus prácticas.

La indagación sobre las culturas políticas resulta relevante pues nos permite «comprender los procesos de construcción de significados de la vida pública (representaciones colectivas, discursos sobre lo público, vocabularios políticos...), y el papel que juegan éstos en los comportamientos y acciones individuales y colectivos» (Morán, 2010:95). Como veremos, los radicales hicieron de la escalada del conflicto su forma de concebir la política y lo político, y desde esa lógica construyeron sus vínculos con otros miembros y organizaciones pertenecientes a los territorios del poder que, de alguna manera, navegaron en aguas teñidas al final de cuentas por una crisis de legitimidad que los mismos radicales contribuyeron a colorear.

La UCRSF integró junto a las facciones conservadoras y la Liga del Sur (LS), antes que un sistema de partidos, una red interpartidaria previa a la reforma de 1912. Dicho de otro modo, los notables se encontraron involucrados en organizaciones partidarias que se expandieron institucionalmente en un entramado faccioso de vínculos competitivos. Pero esta forma notabiliar de pensar y hacer política no resultó refractaria a las innovaciones que acompañaron a las experiencias llevadas a cabo con los nuevos instrumentos prescriptivos de la reforma. En estos años, podemos reconocer una dinámica inherente a la república conservadora que se traducía en pactos entre facciones, movilizaciones, creación de clubes y comités, prensa política como arena de debates, conferencias en bibliotecas y asociaciones, denuncias al gobierno de turno y renuncias a partidos y un ejercicio de la violencia que se plasmó tanto en amenazas de revoluciones como en el ejercicio de las elecciones.

Esta red interpartidaria se configuró como un espacio de intersección de dos tradiciones de socialización política. En primer lugar, se constituyó una tradición patricia - a la que también podemos denominar notabiliar- que articuló la actividad política con la social. En este caso, Macor expresa que «una verdadera red de sociabilidad reunía la limitada actividad del comité, propia de los partidos de notables, con el club social y la vida familiar, y homogeneizaba al grupo de pertenencia facilitando la exclusión de los extraños que no participaban integralmente de la red» (1998:106). En el marco de la tradición patricia, la red social 
— sostenida en relaciones sociales y familiares que acompañó a la vida política de los notables - amortiguó las secuelas de las batallas electorales.

En segundo lugar, como forma de socialización política, la red interpartidaria dará un lugar cada vez más significativo al comité ya que resultaría crucial:

En el proceso de selección de los dirigentes intermedios y en la integración de la militancia partidaria. Con el partido como núcleo organizador se va constituyendo una nueva tradición que [...] no desplazará en importancia los mecanismos de socialización de aquella tradición patricia, que renovará su vigencia en la selección de las élites dirigentes partidarias (Macor, 1998:106).

A partir del entrelazamiento de estas tradiciones, la red interpartidaria contuvo tanto a organizaciones tradicionales - las facciones-como a otras con cualidades un tanto diferentes, como la LS y la UCRSF. En el discurso de los protagonistas, los términos «tendencia» y/o «fracción» hacían referencia, en realidad, a facción como una forma de organización política y mediación entre Estado y sociedad. Sin embargo, los actores no aludían explícitamente a la misma, quizás por la impronta denostativa que conllevaba.

Bajo el imperio del orden conservador que entró en ocaso a partir de 1912, los acuerdos laxos y provisorios que construyeron las facciones se pusieron en juego durante las batallas electorales. Este tipo de articulación desarrollada por las facciones dejó una huella sobre el perfil político argentino que resulta de la conjunción de dos rasgos. Por un lado, el «predominio de las estrategias de conflicto sobre las estrategias de reconciliación, [y, por otro lado, el] estilo excluyente frente al adversario que determina el sentido de la derrota y de la victoria» (Botana, 1988:118). Estos rasgos, durante la democratización política, se encuentran presentes en el radicalismo y en la experiencia política que abordaremos aquí. 


\section{EL REGENERACIONISMO EN EL DISCURSO POLÍTICO}

Como clave para pensar y practicar la política, el regeneracionismo se convirtió en una nota destacable en el horizonte del radicalismo, adquiriendo cierta «regularidad y previsibilidad» (Angenot, 2010) en lo que se dice, escribe y representa. Aunque este temperamento o voluntad regeneracionista, según expresión de Botana (2012), también se encontraba en otras organizaciones políticas lo cual permite considerarlo como «discurso compartido», y por eso mismo un elemento de disputa al momento de las batallas electorales, y que en el caso de los radicales, se articuló con su reciente pasado revolucionario, las instituciones republicanas y la invocación a la patria. ${ }^{1}$ En este contexto, consideramos al regeneracionismo como un componente de la cultura política liberal-republicana, esa gran apuesta a la construcción de la soberanía del pueblo y de una comunidad política integrada por ciudadanos, en la que se combinan instituciones, lenguajes y prácticas, y que otorgó un «sentido» a los comportamientos políticos. El regeneracionismo supuso una percepción de la política y de lo político inscripto en un debate de ideas que involucró a los radicales y los predispuso a establecer articulaciones con pares de otras facciones en pos de concretar la «reparación». Ésta hacía las veces de valor y acción compartida que circuló a través de actitudes, discursos, creencias y sentimientos que conforman la base del orden y el significado del proceso político. Resulta oportuno convocar la perspectiva que propone en otros contextos Marc Angenot para delinear el papel desempeñado, en este caso, por el regeneracionismo:

Hay siempre límites aceptablemente rigurosos de lo pensable... [...] En todas las épocas reina una hegemonía de lo pensable (no una coherencia, sino una cointeligibilidad)... [...] Éste es el axioma: no hay historia «material» [...] sin ideas inextricables pues en discurso, que informan las convicciones, las decisiones, las prácticas y las instituciones... (2010:16)

\footnotetext{
${ }^{1}$ La polisemia del término patria, y su mutación durante el siglo XIX, acompaña a las experiencias políticas y convive en forma ambivalente con la idea de nación. Aquél hace referencia no sólo a una noción territorial más o menos definida — que incluye a la provincia— pero con fuerte referencia sentimental, en ocasiones con componentes de deidad laica, vinculada a una empresa política colectiva. De allí que operó como un término invocativo y de importancia en las prácticas políticas (Di Meglio, 2008).
} 
El tópico «reparación» es constitutivo de la historia escrita por los propios radicales. Desde la producción proveniente de la historiografía militante, la interpretación de Gabriel del Mazo (1955; 1959) retomó el vínculo labrado entre la cronología de la historia argentina y su correlato con la historia del radicalismo. Así, la «Reparación Nacional» constituye un período histórico de la Argentina, enmarcado entre 1889-1891 y 1930. Más aún, «la Unión Cívica Radical está concebida, más que como una parcialidad política, como una Reparación Nacional, para reconstruir la Patria y la Nación sobre sus bases...» (1955, 33-34). Además, del Mazo se esfuerza por dar entidad a la expresión de modo tal que la UCR — que por definición es la encarnación de la reparación-conduciría a la Independencia de un pueblo que merece ser orientado hacia su futuro:

Se llama Reparación porque «repara» o da satisfacción por la ofensa inferida a la nacionalidad, y restablece su nombre, su espíritu y sus fuerzas, y Nacional, porque estaba sofisticada la soberanía de la Nación y había sido desmedrada su Independencia, de tal modo que el abarcamiento de la Reparación comprende al pueblo todo, su honor su vida y su destino (1955:31).

Entre la revolución de 1890 y la reforma política de 1912, las inquietudes en torno de una modificación de las prácticas electorales eran vistas como imprescindibles para una transformación del régimen político. Desde una perspectiva nacional del fenómeno, Martín Castro señala:

Lo que se advertía era una recurrente presencia en el discurso político de intelectuales y políticos de la necesidad de producir una «reacción» o «regeneración» del sistema político que garantice la realización de elecciones libres. Es posible divisar aquí, si se considera que no existe una oposición abierta a la introducción de reformas electorales, cierto divorcio [...] entre un discurso político favorable a las reformas y unas prácticas políticas efectivas que buscan frenar u obstaculizar un proceso reformador. Es evidente que el juego político no se define a partir de facciones que prohíjan la reforma electoral en contraposición a otras opuestas a la apertura del sistema político (2012:83-84). 
Las problemáticas y el clima de ideas que enunciamos se resisten a encorsetarse en los marcos de la cronología política, o a sujetarse a eventos consagrados como verdaderos hitos en la historia argentina y de los partidos. Como ya señalamos, el regeneracionismo implicó una percepción de la política y de lo político inscripto en un debate que involucró a los partidos y sus principales dirigentes. Este debate se tradujo en un conjunto de propuestas comunes, dentro de las cuales se destacó la «reparación», «reacción» o «regeneración patriótica», tornando porosas las fronteras de organizaciones que articulaban experiencias provinciales en diálogo con la dimensión nacional de la política. Esta apuesta, más que definir posiciones, terminó por configurar un discurso que por esos años se vuelve constitutivo de la cultura política (Diego Romero, 2006; Cabrera, 2010), volviendo hegemónica a aquella.

En el pasaje del siglo XIX al XX, el horizonte liberal y republicano experimentó tanto su esplendor como la impugnación de prácticas electorales que expresaban, desde algunas lecturas, la presencia de una crisis de la política, juzgada como crisis moral. En este marco, el regeneracionismo se presentó como una apuesta a la reparación de la política, cuya traducción fue una empresa de reacción que se plasmó en la agenda de experiencias gubernamentales. En esta clave, José Luis Romero advirtió que «el "espíritu del Centenario", nacido de múltiples factores se incuba a partir de la crisis que la oligarquía predominante sufre en 1890, tanto en su estabilidad política y social como en sus convicciones y perspectivas». Ese vasto movimiento de disconformismo se prolongó sobre el inicio del siglo $\mathrm{XX}$ «expresando un vigoroso aunque contradictorio sentimiento colectivo...» (1998:59). No obstante, esta corriente de pensamiento no colocó en tela de discusión las grandes líneas trazadas por el ideario positivista y liberal que dieron lugar a la construcción de la Argentina moderna.

La impresión de crisis política y moral que experimentaron algunos actores fue producto tanto del malestar generado por las prácticas del régimen representativo bajo el imperio de los gobiernos conservadores, como de las profundas transformaciones sociales propias de la madurez de un orden burgués. En ese «espíritu del Centenario», que articuló el pasaje del siglo XIX al XX, la apuesta a una reparación indicaba una lectura de ese presente que, apelando a un pasado para buscar en él aquello que merecía ser rescatado, otorgaba un nuevo vigor a la vida política futura. 
La idea de crisis - que los contemporáneos visualizaron como general y que dio lugar a un discurso de corte decadentista (Terán, 2008)— resulta fundamental porque permite captar la dimensión temporal implícita en la noción de regeneración. Según la definición de Natalio Botana — que delimita sus alcances diferenciándola de la noción de reformismo- «mientras el reformista está inspirado en una concepción del cambio que tensa su mirada hacia el porvenir en busca de nuevas instituciones y de un reordenamiento progresivo del poder social, el regeneracionista se empeña en poner en buena condición una cosa deteriorada» (2005:122). ${ }^{2}$

De esta manera, el regeneracionismo ocupó un lugar central en el lenguaje político de la Argentina finisecular, aunque con vaivenes en tanto fue reivindicado con mayor o menor énfasis por un número variable de actores, y reveló «el conjunto de premisas compartidas sobre las cuales pivotea el discurso público de una época, y cómo estas premisas se van alterando en el transcurso del tiempo» (Palti, 2005:32). Sólo así puede entenderse la vitalidad que tuvo como principio de legitimidad para la acción de los radicales, llegando a ser una consigna que excedió a este partido, aunque éste la concibiera con exclusividad.

La singularidad del vínculo al calor de las revoluciones entre radicalismo y regeneracionismo, consagró una imagen de la UCRSF y de la UCR como portadoras de la bandera de la reparación institucional hasta el punto de convertirla en un elemento identitario de su existencia partidaria. En esta lógica, la reparación del sistema republicano-representativo y del régimen federal — justificativo en muchas oportunidades de los alzamientos cívico-militares protagonizados por los radicales - se convirtió en el precepto para superar la crisis moral y política. Una acción regeneradora de estas características no encontraba, según los radicales, su lugar en la agenda de los gobernantes y precisamente éste era el sitio que aspiraban a ocupar como baluartes de la voluntad popular.

\footnotetext{
${ }^{2}$ En el caso español, el regeneracionismo adquiere un sentido más amplio aunque contempla entre sus componentes esa pretendida maldad del sistema político como así también una supuesta enfermedad de la nación española o lugar de España en la Europa de principios del siglo XX. Para Vicente Salavert Fabiani y Manuel Suárez Cortina, «[p]roveniente del mundo médico, la idea de regeneración remite a una pretendida descomposición de un medio, cuya supervivencia reclama una acción terapéutica, de aplicación de remedios urgentes que en su metáfora clínica remite a la cirugía, a la acción firme contra lo que se pretende pueda ser una enfermedad del cuerpo social y político» (2007:10).
} 


\section{DEL SITUACIONISMO AL TRIUNFO RADICAL}

La gestión del gobernador conservador Ignacio Crespo (1910-1911) venía también a «reparar» e iniciar la empresa de construcción de nuevos elementos de legitimación para el régimen político. En diferentes momentos de su gestión, hasta la intervención federal, la prensa recalcaba la complementariedad de propósitos regeneracionistas entre el gobernador y el presidente de nación Sáenz Peña - en el marco de los debates parlamentarios que dieron lugar a la reforma política de 1912 - con respecto a tres cuestiones: el voto, la representación de las minorías y la formación de un partido orgánico. El diario Santa Fe colocó en un mismo plano a los mencionados a partir de un común espíritu regeneracionista:

Han de fracasar las maquinaciones de los políticos a la antigua usanza, contra el gobierno del ilustre ciudadano que con toda valentía afronta el problema de la regeneración cívica del país, barriendo las prácticas añejas de funesta recordación... En nuestra provincia [...] se ha iniciado la misma lucha, pero el triunfo final se descuenta de antemano; el pueblo quiere gobiernos dignos de un progreso y civilización, como lo son, en el orden nacional el gobierno del doctor Roque Sáenz Peña y en el provincial el del señor Ignacio Crespo. ${ }^{3}$

Hasta 1912, la UCRSF participó de manera interrumpida en los comicios provinciales - o al menos no portando aquella sigla, o integrando agrupaciones típicas de la política notabiliar como Unión Provincial - tanto por su devenir entre la participación y la abstención, como por los efectos del control electoral impuesto por el «situacionismo». ${ }^{4}$ Así, la abstención electoral y las acciones revolucionarias otorgaron al radicalismo dos fuertes rasgos identitarios que lo distinguieron de los partidos conservadores. El radicalismo siguió esgrimiendo una posición regeneracionista pero vinculada con la consecución de un destino misional de engrandecimiento de la nación. La UCR, a través de su comité nacional, confirmó:

\footnotetext{
3 «Consecuencia lógica», Santa Fe, 03/03/1911, p. 1.

${ }^{4}$ Denominación que hacía referencia a los partidos de notables que desde fines de la década del sesenta del siglo XIX ejercieron el control político en la provincia. A partir de esta expresión derivó el término «situacionistas» para denominar a miembros de las diversas facciones santafesinas.
} 
Su decisión de persistir en la lucha dentro de la severidad moralizadora de sus principios hasta conseguir, por el esfuerzo viril de sus conciudadanos, que la República sea reintegrada a la plenitud de sus libertades y que la vida cívica reconquiste los prestigios de austeridad democrática de que la ha privado la corrupción de gobiernos y partidos. [...] Es grato señalar la persistente lucha por la causa de la reacción nacional en el sentido de disciplinar una fuerza moral y política con aptitud para la defensa de los derechos del ciudadano... [...] En el impersonalismo de su programa no rebaja al nivel de un debate sobre personas la gran contienda por el triunfo de los anhelos de reparación política y administrativa que palpitan en el alma nacional. [...] Considera verdad inconmovible que orden y probidad en las finanzas, patriotismo en vida pública, justicia recta, educación bien inspirada y adecuada distribución de las riquezas y progresos, harán que una nueva vida penetre en nuestras instituciones inertes para transformarlas en un organismo poderoso que levante nuestra Patria al lugar que le corresponde en el mundo 5 .

En este manifiesto puede reconocerse una serie de tópicos que articulaban elementos novedosos junto a otros que ya se encontraban en el discurso político a la salida del siglo XIX. La idea de reparación, como efecto de las prácticas de gobiernos y partidos que condujeron a la crisis de la patria, convirtió al radicalismo en el adalid de una cruzada moral — con atisbos discursivos de corte guerrero- para la reconstitución de la República de la mano de una vida política con la vigorosidad que debía aportar el libre ejercicio del sufragio. Pero en el caso santafesino, la abstención no fue absolutamente practicada pues en alianza con fragmentos de la galaxia conservadora la UCRSF integró alianzas electorales, cuestión que marcó diferencias respecto de la UCR. De esta última,

${ }^{5}$ «Manifiesto del Comité Nacional al reorganizarse», Buenos Aires, 29/02/1904 (Del Mazo, 1957:323-327). Pocos años más tarde, el líder del radicalismo ratificó estos principios: «Su causa [la de la UCR] es la de Nación misma y su representación la del poder público. [... ....somos legionarios de la sacrosanta causa por que nos debatimos en bien de todos, desde que es por y para la Patria. Relevantes inspiraciones y justísimos anhelos de reparación es lo que anima e induce a ese movimiento... [...] Ella [la UCR] constituye una de esas exteriorizaciones públicas de aspiraciones morales que distingue a los movimientos bienhechores de la humanidad...». «Primera carta de H. Yrigoyen a P. Molina», Buenos Aires, 21/09/1909 (Del Mazo, 1957:118-132). 
[E]l yrigoyenismo valoró muy pronto el potencial explosivo de una táctica que erosionaba el régimen político, de allí el rechazo a todo intento de composición con el gobierno de turno, el castigo autoritario de cualquier cuestionamiento interno de esta política y la negativa de cualquier tipo de coalición con otras fuerzas opositoras. De allí también la ausencia de programas fuera del reclamo de la Constitución y el sufragio libre... (Aboy Carlés, 2001:88-89)

Fue en este proceso de construcción, deconstrucción y reconstrucción de instituciones partidarias de la galaxia conservadora en el que coexistieron viejas y nuevas prácticas, donde reaccionar o regenerar constituyó una argumentación —como hecho histórico y social (Angenot, 2010) - que «dijo» sobre la política y sus prácticas en un derrotero de reformas desde arriba, como el reformismo conservador, e impugnaciones desde abajo, como las revoluciones radicales. Como afirma Elías Palti:

[U]n lenguaje político no es un conjunto de ideas o conceptos, sino un modo característico de producirlos. Para analizar un lenguaje político de un período no basta, pues, con analizar los cambios de sentido que sufren las distintas categorías, sino que es necesario penetrar la lógica que las articula, cómo se recompone el sistema de relaciones recíprocas. (2007:17)

El conjunto de dispositivos que se pusieron en práctica en Santa Fe a partir de la intervención federal en 1911 que dio fin al gobierno de Crespo como resultado de un conflicto internotabiliar aspiraba, como expresan Persello y de Privitellio al analizar el escenario nacional, a que las nuevas reglas electorales favorecieran «la capacidad creadora de la virtud ciudadana» y «hacer del comicio una práctica regulada y esencialmente pacífica» (2009:106-107). En la lectura de los regeneracionistas, la reforma era el camino hacia la reparación pues daría lugar a la práctica electoral impoluta. En la optimista —más aún, idealistaperspectiva regeneracionista, la acción corruptora de los gobernantes «no ha llegado a infectar a la mayoría del cuerpo social. La sociabilidad argentina es el reservorio de la conciencia, de la moral y de la razón» (96), de tal modo que es la sociedad el punto de emanación de la regeneración que la política espera. 
Para el Ejecutivo nacional resultaba crucial lograr la concurrencia a la arena electoral del radicalismo. En esta clave, a pocos días de decretarse la intervención federal, el diario La Capital expresaba que la designación del interventor Anacleto Gil «no tiene otro propósito que llevar al gobierno de esa provincia al partido radical. Con ello cumpliría la promesa que hizo al |jefe de ese partido en una conferencia.... ${ }^{6}$ El nuevo escenario colocaba al radicalismo en un lugar que lo obligaba a poner en acto su lectura sobre la política y sus prácticas, pero también implicaba plasmar los efectos de la reforma. Comentarios similares formulaba el periódico Santa Fe: «El presidente de la república está vivamente interesado en incorporar esa fuerza viva y ponderable a la actividad eleccionaria y con tal de conseguirlo hará cuanto esté en su mano porque el suceso se produzca». ${ }^{7}$

Ante la inminencia de una convocatoria a elecciones provinciales, la UCRSF pareciera diferenciarse de la UCR y de la perspectiva yrigoyenista tan férreamente expuesta en diversas instancias, al diseñar un programa electoral preciso y salir así de la declamada abstención. Como señalan autores ya referenciados:

[E]l yrigoyenismo constituyó una forma de identidad que se vinculaba con el sufragio de una manera a la vez novedosa y tradicional. Tradicional, en tanto incluía una dimensión regeneracionista ya ampliamente instalada en la opinión; novedosa, por la identificación absoluta de la regeneración con el partido y por la construcción de un liderazgo mesiánico que, utilizando lenguajes religiosos, terminaba por asociarla con una personalidad salvadora y providencial. (Persello y de Privitellio, 2009:110)

El triunfo de la UCRSF en la elección de 1912 expuso un conjunto de prácticas y estrategias destacado en otros escritos (Carrizo 2013; 2014; 2017), y que aquí solo mencionaremos en forma somera: las pegatinas en los muros, la distribución de folletos, el almuerzo criollo con empanadas y asado que convertía en público de los discursos a los comensales circunstanciales, las manifestaciones hacia la plaza —el número de asistentes era de importancia tanto para los organizadores como para la prensa-, las giras por las localidades - para inaugurar comités y organizar el trabajo electoral- y las conferencias o discursos de los candidatos o

\footnotetext{
${ }^{6}$ «La intervención y su personal», La Capital, 18/04/1911, pp. 6-7.

7 «Ecos del día: El partido radical», Santa Fe, 19/04/1911, p. 3.
} 
de miembros de los principales comités. A través de la combinación de nuevas lealtades que se complementaban con otras preexistentes, se articulaban los vínculos entre los referentes políticos con militantes y adherentes de distinto grado. En la construcción de esta red cobraban preponderancia los caudillos electorales debido a las tareas que desempeñaban desde los comités, como así también a los notables.

Así, esta experiencia electoral habría permitido no sólo aglutinar cierta imagen de sí que estaba construyendo el partido a partir de la exaltación de las revoluciones y del abstencionismo, sino que además coadyuvó a la construcción de una identidad a través de discursos atiborrados de reconstrucciones, resignificaciones, valoraciones por parte de los propios dirigentes y militantes del partido, elaboradas y trasmitidas tanto en una alocución en un palco luego de una movilización como en una conferencia en un comité parroquial. No es un detalle que la UCRSF elaboró una plataforma política en vista de las elecciones de 1912, enunciada como programa político por parte del candidato a gobernador. Resultaron también relevantes los pactos entre las UCRSF y distintas facciones conservadoras (constitucionales y coalicionistas) que pueden observarse al analizar los resultados en diversos departamentos de la provincia, en particular Rosario y La Capital (Carrizo, 2014).

La consagración de la fórmula de gobierno Menchaca-Caballero se llevó a cabo en un clima atravesado por "el cisma radical», expresión que aludió a las tensiones que anidaban en el radicalismo desde la misma definición de la fórmula realizada por la convención. ${ }^{8}$ Hasta el 7 de mayo inclusive, día de la reunión del colegio electoral, se sucedieron innumerables reuniones para lograr los acuerdos entre grupos del mismo partido. Días previos a la reunión del colegio electoral, tanto la dirigencia del radicalismo nacional como la del radicalismo entrerriano se desempeñaron como mediadoras para llevar a buen puerto la consagración de la fórmula gubernamental ante la posibilidad de que los electores, que respondían a diferentes tendencias radicales, se presentaran divididos.

Al final de cuentas, los electores radicales votaron por la fórmula consagrada por la convención a cambio del compromiso de Menchaca de «cumplimiento íntegro del programa radical» solicitado por la UCRSF, además de la consideración de ciertas demandas para la conformación del gabinete y la estructura de 
gobierno. Por un lado, los propósitos que emanaban del programa apelaban e interpelaban a todos los sectores sin apuntar a ninguno en particular y sin que se explicitara rechazo por alguno en forma específica, a excepción del «círculo corrupto» -en clara alusión a los situacionistas-, blanco de la mayoría de las impugnaciones. Las metas enunciadas por el candidato en su discurso-programa otorgaban a la creciente trama organizacional del partido una dimensión ideológica que viabilizaba todavía más el proceso de construcción de una identidad política: «ser radical». Pero además, una problemática inicial se centró en torno a la conformación de la burocracia, convertida en campo de batalla en vista de resolver quiénes serían sus ocupantes: «los más aptos» o «los radicales». En este sentido, algunas de las figuras ministeriales eran cercanas al recientemente electo gobernador, otras a la dirigencia de mayor peso en la UCRSF, lo cual otorgó una intensa dinámica entre gobierno y dirigencia partidaria.

\section{FACCIONES Y GOBIERNO RADICAL}

El discurso de asunción del gobernador expuso el inicio de una nueva época para la nación, de la mano del partido radical, tal como quedará instalada en la conciencia histórica de la sociedad argentina y en la historia del radicalismo:

El momento político actual es sin ninguna duda un momento histórico que marca para la nacionalidad argentina la iniciación de una nueva era. El Partido Radical consuma después de muchos años de labor y sacrificios una gran obra de aliento. [...] Si luchó persiguiendo la honestidad, hoy buscará ese elemento y la competencia como condiciones indispensables para el desempeño de las funciones públicas. Para los que esperan confiados en programas y promesas les señalo mi programa de candidato que confirmo y ratifico como gobernador...9

${ }^{9}$ «La transmisión del mando», La Capital, 10/05/1912, p. 6. 
Sin embargo, las tensiones entre las facciones radicales ordenaron el devenir del nuevo gobierno, de tal modo que las referencias a «tendencia», "fracción» y «cisma» aparecieron en la prensa sin solución de continuidad. Las prácticas llevadas a cabo por las facciones radicales continuaron siendo las habituales: publicación de manifiestos de renuncia a comités, movilizaciones seguidas de arengas, impugnaciones desde periódicos (por ejemplo, El Mensajero y La Democracia, voceros de los radicales rosarinos y santafesinos) a los que se sumaron las denuncias al comité nacional de la UCR en torno a qué significaba "ser radical», junto con la aspiración de constituirse en la facción legítima.

Al calor del ejercicio de la experiencia gubernamental y de los vínculos con la UCRSF, ciertos calificativos enunciados desde una lógica binaria (correligionarios-traidores; moderados-intransigentes; ortodoxos-heterodoxos, guardia vieja-juventud; puros-overos) se fueron delineando las facciones que aspiraban a legitimarse a partir de una apelación al vínculo entre política y patriotismo. La invocación adquiría la condición de esa unión deseable entre moral y política tal como proponía el regeneracionismo, y el resultado de dicha conexión significaba «la postergación de pasiones e intereses de círculos o personas», como expresaba la prensa. Así, el fenómeno de la representación política en la Argentina moderna parecía adquirir un tono casi espiritualista invocando al «alma de la nación» (de Privitellio, 2004).

En el período que se centra este escrito, el radicalismo al calor de sus triunfos electorales y de un discurso político eficaz selló muy efectivamente el vínculo con la nación. Pero la aspiración omnicomprensiva con la que se definía (Ansaldi, 2000), era necesario delimitar quiénes eran los que podían ser incluidos y quiénes no poseían las credenciales para ser parte de la organización partidaria. La lucha por la posesión de las «banderas del Parque», pasaporte hacia la «causa», adquiría un plusvalor para definir el lugar legítimo que ocupaban las facciones dentro del radicalismo que, pese a su enunciación en singular, no alcanzaba a disimular el plural. Es decir, nos encontramos frente a «radicalismos», con un grado de antagonismo en sus vínculos propio de la lógica de la guerra.

La prensa denominaba «tendencia» o «fracción» a los diversos grupos radicales -antes que organizaciones partidarias - que, con una precaria institucionalización, se congregaban alrededor de un notable en pos de las batallas electorales. 
El Santa Fe exponía una caracterización de las instituciones partidarias: ${ }^{10}$

Nadie es servidor de un programa: es miembro de una facción, y tiene como objetivo el engrandecimiento de un hombre. Santa Fe no tiene partidos, tiene cuadrillitas [...] Las facciones personales empequeñecen el escenario. Los hombres graves huyen de la acción ciudadana, porque les asquean esos cotos cerrados, sin luz y sin horizonte. ${ }^{11}$

Entre 1912 y 1914 las facciones radicales que se constituyeron («menchaquistas» o «gubernistas» que respondían al gobernador, en creciente vinculación con Hipólito Yrigoyen; «ignacistas» o «principistas» que seguían al principal referente de la historia radical desde los años revolucionarios, Ignacio Iturraspe, y «caballeristas» que respondían al vicegobernador) no poseyeron fortalezas institucionales ni cohesión, con la relativa excepción de los radicales que contralaban la UCRSF. No obstante, guardaban entre sí un conjunto de rasgos más o menos comunes: organización a partir de un notable con un recorrido por la red interpartidaria, movilidad horizontal entre referentes al calor de las innovaciones que producían las campañas y los resultados electorales, disputas por la posesión de las banderas identitarias, mutua adjudicación de términos para legitimar y/o deslegitimar a propios y ajenos. En este sentido, resulta acertada la imagen de «doble pasaje» que emplea Ana Virginia Persello para ilustrar esta Argentina circa 1910-1916, y que consideramos de oportuna aplicación para el caso santafesino:

Doble pasaje del «régimen de notables» a la «democracia de partidos» y del partido radical de la oposición al partido en el gobierno marca la persistencia de prácticas anteriores, inscriptas en la tradición facciosa del siglo XIX, y ahora asimiladas en cada uno de los partidos, que identitariamente pujan por presentarse como una unidad. (2004:54-55)

Al final de cuentas, el reformismo conservador puso sobre el tapete dos interrogantes inherentes a la vida política. Si era factible el cambio en las prácticas de la clase gobernante a partir de una nueva relación entre moral y política —como

\footnotetext{
${ }^{10}$ El término empleado mayoritariamente por los diarios era «tendencia». Más aún, en el discurso la palabra «facción» era antítesis de «patria»y «partido orgánico».

${ }^{11}$ Cf. «Las cuadrillitas», Santa Fe, 04/10/1914, p. 2.
} 
era propuesto por el regeneracionismo - a partir de los propósitos de la reforma de 1912. El interrogante se vinculaba con otra de similar importancia: si era posible un vínculo distinto entre clase política y partido, lo cual se articula con las complejidades del pasaje de un régimen de notables a un régimen de partidos.

Una inicial problemática en torno de la legitimidad de ejercicio, referenciada párrafos antes, se centró en torno a la conformación de la burocracia. De este modo, se presentaban sin tapujos los vínculos entre la UCRSF y el gobierno provincial lo cual colocó en debate la viabilidad de los fines últimos del radicalismo que, a su vez, lo hacían partícipe de la ola regeneracionista. La conexión entre moral y política, que otorgó legitimidad al radicalismo en el llano, se presentaba así con otro significado pues la distribución de los incentivos materiales puso en permanente tensión el vínculo del gobierno con el partido. ${ }^{12}$

De a poco, el gobernador se posicionaba frente a la UCRSF de tal modo que buscaba no someterse a la presión de los comités y los caudillos, incluso parecía imponer «su propia gente» a partir de garantizar la estabilidad laboral. Este mecanismo habrá viabilizado la construcción de lealtades hacia Menchaca, tanto por la convencional vía del otorgamiento de cargos como a través de la ratificación en la continuidad en los mismos. La compleja resolución del vínculo entre los propósitos políticos de la nueva gestión y la distribución de los incentivos materiales se tradujo, por ejemplo, en el notorio descontento del magisterio debido a que los ascensos eran decretados por el Ejecutivo a propuesta del Consejo de Educación - los nombramientos para ocupar direcciones de escuelas eran por recomendación, ${ }^{13}$ como también la definición de los traslados docentes. ${ }^{14}$ También, tal como expresaba la prensa, el paso por las «horcas caudinas» de aquellos empleados que «equivocaron el pálpito y votaron contra el gobierno» de Menchaca, los ubicaba en los márgenes de la continuidad laboral en la admi-

\footnotetext{
12 Según lo estipulado por el programa radical, la ocupación de un puesto en la administración pública implicaba la renuncia a cargos en los comités. Cf. «Reorganización radical», Santa Fe, 25/06/1912, p. 1. Además uno de los principios del radicalismo consistía en la renuncia a percepción de dieta alguna al momento de ocupar una senaduría o diputación según también lo establecía el programa del partido. Cf. «Una cosa es hablar de muerte...», Santa Fe, 22/10/1912, p. 1.

13 «Una queja fundada», Santa Fe, 22/03/1912, p. 1.

14 «El Maestro rural», Santa Fe, 14/05/1912, p. 5; «Desgobierno escolar», Santa Fe, 11/03/1913, p. 1.
} 
nistración pública. ${ }^{15}$ A su vez, el patronazgo del Estado acrecentaba las «cajas» de los comités que se posicionaron como leales al gobernador. A través del pago de sueldos se produjo una redistribución de recursos financieros desde el Estado a los comités por medio de dos mecanismos: la cesión de la «primicia» - primer sueldo que se cobraba - y del «diezmo» — una proporción mensual del sueldo según la categoría del empleo. ${ }^{16}$

Durante los años del gobierno radical, la UCRSF era un partido que conservó rasgos de una organización aún tradicional. Los «principios» o la "causa» como constitutivas del regeneracionismo y como horizonte partidario todavía no terminaron de ganar la pulseada frente a los personalismos, más aún su convivencia era inherente a las formas de organización de la institucionalidad partidaria. Así, ya en 1913 Ignacio Iturraspe —uno de los principales dirigentes desde los años noventa- protagonizó una primera escisión importante. Con este notable a la cabeza, el radicalismo «principista» buscó acelerar el ritmo de su institucionalización al calor del distanciamiento con el gobernador, e invitó a sumarse «a los radicales de verdad y a todos los ciudadanos que simpaticen con la causa....". ${ }^{17}$ Esta escisión iba en paralelo a la impugnación al radicalismo gubernista que respondía al gobernador, al que calificaron como «situacionista» en virtud de su acercamiento a dirigentes conservadores.

Los resultados de las batallas electorales -legislativas provinciales y nacionales - consolidaron al radicalismo gubernista, y relegó a otras facciones al campo de la oposición, junto a otros partidos y fragmentos del situacionismo que en ocasiones dieron lugar a coaliciones. De todas maneras, la conquista de los espacios de poder implicó que la UCRSF contuviera a todas las facciones radicales — menos la principista - en las elecciones de 1914. Ante el desafío de las urnas, la plasticidad de la organización se demostraba al momento de articular las facciones con un estilo similar al de los partidos conservadores. Los acuerdos, alianzas, pactos y promesas junto a las tensiones, escisiones y fracturas resultaban cualidades inherentes al radicalismo. La defensa de la «causa» se transformó así en una bandera o slogan que asomaba intermitentemente.

\footnotetext{
15 «Las horcas caudinas», Santa Fe, 11/01/1913, p. 1.

16 «Ecos del día. El diezmo radical», Santa Fe, 17/01/1913, p. 5.

17 «Día político. La renuncia de Iturraspe», Santa Fe, 16/02/1913, p. 1.
} 
Un rasgo propio de los escenarios donde discurre la política - como el electoral - es su incertidumbre ya que son potencialmente mudables ritmo de los cambios que sufren los posicionamientos de sus protagonistas. Como ya se expuso, un elemento que atravesó el período fue el tenso vínculo entre radicales. Ya en noviembre de 1914, luego de las elecciones legislativas y a poco menos de dos años de iniciarse el gobierno radical, se dio a conocer un manifiesto de la junta de gobierno de la UCRSF en el que se explicitaba el distanciamiento entre partido y gobierno. La junta, en uso de los atributos que le confería la carta orgánica, se reunió en Rosario y no en Santa Fe. Sin embargo, ciertas voces radicales expresaron que el máximo órgano partidario había actuado sobrepasando sus atribuciones ya que sólo se reunieron tres de sus miembros, objeción que no necesariamente se basaba en los lineamientos prescriptivos de la carta orgánica. Otro factor de impugnación a la junta radicaba en que, según la carta orgánica, la misma había caducado el 30 de julio de 1914 y no se había producido la renovación de sus integrantes. ${ }^{18}$

En el manifiesto de referencia — que recibe los apoyos del senador José Camilo Crotto, miembro de la mesa directiva nacional de la UCR, y del vicegobernador Caballero que junto a Rodolfo Lehmann reorganizó los comités de la facción «disidente» que encabezaban en la capital de la provincia- la junta exponía las diferencias que mantenía con el gobierno radical:

Que el gobierno de Santa Fe emergido originariamente de los esfuerzos llevados a cabo por la UCR debió tener como propósitos fundamentales la realización de los anhelos de reparación moral e institucional que siempre fueron la razón primordial de su existencia; cumpliéndolas con las mismas integridades que impertérritamente constituyen su regla de conducta. [...]...el gobernador de la provincia no requirió en ningún momento el juicio ni el consejo de la dirección de la UCR al tomar las medidas administrativas y políticas...

${ }^{18}$ Cf. R. Villarroel, «Santa Fe. I. La opinión de un radical», Revista Argentina de Ciencia Política, 30/10/1914, T. IX, pp. 322-323. 
La junta de gobierno, en nombre de la UCR de la provincia declina toda responsabilidad en los sucesos ocurridos; declara que no se solidariza política ni administrativamente con el gobierno. Y como siempre, se ratifica en los propósitos de proseguir su acción reparadora que tiene el deber de continuar... ${ }^{19}$

Con este pronunciamiento, la UCRSF definía al gobierno como carente de legitimidad de gestión precisamente porque su ejercicio del poder se había llevado a cabo desconociendo los altos principios del partido. En otras palabras, el partido se presentaba como cualitativamente distinto y, a su vez, como un lugar de refugio del propio radicalismo y de las grandes metas que habían dado sentido a su historia. La UCRSF adquirió, entonces, un doble perfil: era un objeto valioso en sí pero también constituyó una catapulta para la prosecución de los grandes principios por parte de los dirigentes que la orientaban. Los «bandos» — como los define la prensa - disidentes y gubernistas estaban claramente cristalizados al interior del radicalismo. A la luz de la disputa, resultaba evidente que la facción disidente operaba desde la UCRSF empujando a la facción gubernista fronteras afuera. Por su parte, esta última maniobraba desde el gobierno pero dejaba al desnudo las limitaciones del radicalismo en su empresa de reparación, leitmotiv de su presencia en el escenario electoral.

La lógica facciosa expuso, sin lugar a dudas, la fortaleza de los radicalismos al calor de las batalla electorales de 1916. En esta puja, es posible observar un particular discurso entre los radicales, por ejemplo, el reemplazo en el discurso político de «gobierno de Santa Fe» por enunciados como «círculos oligárquicos y corruptos». A su vez, el rescate que realizaba la UCRSF de un relato modélico que incluía a «mártires» que habían realizado «esfuerzos» en el pasado en pos de los anhelos de «reparación moral e institucional», al tiempo que impugnaba a los «traidores» del gobierno. Estos elementos ofrecieron las condiciones para la conformación de una memoria conminatoria que legitimaba, al calor del vínculo entre gobierno y partido, sólo a algunos radicales a la vez que expulsaba a otros al terreno de lo espurio.

\footnotetext{
${ }^{19}$ «Ecos del día. El manifiesto de la junta de gobierno del partido radical», Santa Fe, 11/11/1914, p. 4. Cf. «La situación política. El manifiesto radical», Santa Fe, 12/11/1914, p. 2. Cf. «Notas», Santa Fe, 15/11/1914, p. 2.
} 
La dinámica de los acontecimientos implicó una serie de intervenciones al partido, negociaciones entre dirigentes de la UCR y de la UCRSF, entre referentes del gobierno y de la dirigencia radical nacional, entre legisladores nacionales y provinciales. El vínculo nación-provincia se plasmó en las futuras elecciones para gobernador y, luego, presidente de la nación. Pero la lucha electoral oficiaba como un manto que cubría la lucha facciosa, y la posibilidad de embanderarse en torno de un objetivo patriótico se constituía en elemento aglutinante de los «pasionismos», como expresaba la prensa. Esa proximidad de la lucha electoral entraba en articulación con la lógica facciosa que a la vez, como sostiene Gerardo Aboy Carlés, convivía con la capacidad de «crear sentido o significación» al calor de una institución partidaria controlada por unos y negada a otros, al tiempo que ambos aspiraban a formar parte de la misma identidad política. De esta manera es: "como se articulan los espacios de homogeneización o afinidad interna y de diferenciación respecto a un exterior que es constitutivo de cualquier identidad social en tanto sedimentación de poder; es así como toman forma las asociaciones y disociaciones políticas» (2005:129).

A esta altura de los acontecimientos, la facción gubernista se propuso transitar el camino de la construcción de una nueva organización partidaria — sin negar su pertenencia al radicalismo-, que represente sus propios intereses en la venidera competencia electoral. A través de la prensa, ${ }^{20}$ los gubernistas no renegaban en su discurso su pertenencia a la identidad radical. Encontramos una discursividad en la que se presentan, también aquí, «mártires» que indicaban el camino para la restauración nacional, por lo que la regeneración en la retórica radical se presentaba como empresa integral. Pero al mismo tiempo, esa identidad se definió con un fuerte sentido de exclusión y deslegitimación respecto de los radicales disidentes, esos «hermanos que habían equivocado el camino» pero que tenían la oportunidad, en la batalla por el poder, de purificarse. La identidad política del radicalismo poseía, entonces, esa doble capacidad de configurar un sentido pero también un proceso de diferenciación interna y externa respecto de los propios radicales.

Las dirigencias que orientaron cada facción se esmeraron en la apropiación de los dispositivos simbólicos para orientar la sensibilidad colectiva de los radicales que les respondían, al mismo tiempo que les permitió afirmarse en sus propias

20 «Movimiento político. La reunión radical de ayer. El manifiesto», Santa Fe, 30/07/1915, p. 2. 
acciones. Ese pasado revolucionario y abstencionista había legitimado, de una manera casi sacra, la oposición de los disidentes respecto de los gubernistas. Con esta impronta el radicalismo contribuyó a la construcción de una cultura política en la que se presentaba como la encarnación de la salud política de la nación. Pero además, en el discurso político y en las representaciones de los actores, la violencia conservó un lugar relevante al momento de definir las posiciones de unos ciudadanos que no descartaron el uso de la fuerza en la discursividad, en principio, pero que era constitutiva en la historia reciente de la vida política. Por ejemplo, el dirigente de la UCRSF Néstor de Iriondo expresó:

Tendremos que medir nuestras armas con las de un régimen dentro del cual hay un gobernador que quiere sucederse, perpetuando su influencia personal, jefes políticos que [...] preparan la máquina eleccionaria, caudillejos de aldea [...] y tras ellos, un conglomerado que ha hallado en las esferas del poder, jordanes maravillosos de donde salen redimidos de toda mancha... ${ }^{21}$

En el flujo y reflujo de protagonistas, la ocupación de espacios institucionales y los discursos, la UCRSF exponía la aspiración de mantener algún tipo de vínculo con la UCR y, en el mismo sentido, libraba una disputa por la posesión del "sello» y tópicos del radicalismo. Por ejemplo, los valores fundacionales de corte regeneracionista que, para los disidentes, no habían sido la bandera de la gestión gubernamental, hasta el punto de considerar al gobierno de Menchaca como una continuación del situacionismo. En este punto, resulta interesante evaluar en qué grado ese era un reclamo que apelaba a los principios éticos o «espíritu» originarios del radicalismo, o sólo un intento de apropiación de la identidad, de la mano con la necesidad de evitar la pérdida de control sobre la UCRSF respecto de los gubernistas. De esta manera, en la antesala de las elecciones, el discurso de los disidentes enarboló las banderas de la UCRSF — que también eran las de la UCR - y vinculó política y moral como forma excluyente de legitimar no sólo su posicionamiento, sino también la aspiración a la gobernación. Pero, al mismo tiempo, buscó marcar una indudable diferencia con los radicales gubernistas, a 
quienes responsabilizó de poner en riesgo la existencia misma del partido, situación que, de no mediar la irrupción de la UCRSF, colocaba en peligro el alma de la nación.

La elección para la renovación del poder ejecutivo santafesino y de legisladores provinciales se realizó el 6 de febrero de 1916. El escenario electoral tuvo protagonistas conocidos, con profusos recorridos en la red interpartidaria, la sociabilidad patricia y el comité. Las organizaciones que se presentaron en el escenario electoral fueron la UCRSF, la UCR, el Partido Demócrata Progresista, la Unión Provincial denominados «freyristas» en referencia al ex gobernador Rodolfo Freyre, cabeza política de la facción - y el Partido Socialista. Los días previos al comicio en los diarios se reprodujeron un sinnúmero de denuncias sobre la intervención del poder ejecutivo en el proceso electoral que, se decía, venía a repetir y hasta superar las prácticas del régimen oligárquico. Por ejemplo, La Capital expuso:

Al margen de estas intensas manifestaciones del civismo argentino que reconfortan el espíritu y despiertan bríos, hay que lamentar sensiblemente el espectáculo vergonzoso que están dando las policías electoras de la campaña santafesina cuya injerencia directa y abusiva en la presente contienda electoral ha calumniado extraordinariamente en forma tal que a pesar del ingrato recuerdo de las oligarquías de antaño, los sucesos de tal índole actualmente no tienen precedentes. Esta nota discordante es obra del primer gobierno radical de la república, ejemplo más que suficiente para orientar la acción ciudadana y señalar el mejor camino a los que se disponen a cumplir conscientemente los deberes cívicos del momento. ${ }^{22}$

Por su parte la UCRSF — cuyos integrantes se autodenominaban los «verdaderos radicales» - apostaron al triunfo impugnando al gobierno. En este sentido, los disidentes de Rosario manifestaron:

Santa Fe dividida por la acción de un gobierno que nacido del seno del partido obra y actúa en pugna con los principios que constituyen la plataforma del mismo, hace que los verdaderos radicales busquen solidarizar su acción al lado de los hombres que por su tradición son garantía de lealtad... ¿Habíamos de permanecer cooperando al

${ }^{22}$ La Capital, 06/02/1916, p. 6. 
resultado de una fórmula que en síntesis es la representación genuina de un sistema político repugnante a las prácticas y moral del radicalismo? Como radicales [...] no podemos prestarle nuestro concurso porque ello significaría una traición a los ideales por los que hemos luchado durante toda nuestra vida política. ${ }^{23}$

Existió un evidente esfuerzo por parte de los radicales disidentes por exponer un discurso institucionalmente instalado desde el partido cuya sigla no estaban dispuestos a perder. Como todo discurso social, estuvo provisto de aceptabilidad y encanto, «tiene eficacia social y públicos cautivos, cuyo habitus dóxico conlleva una permeabilidad particular a esas influencias, una capacidad de apreciarlas y de renovar su necesidad de ellas» (Angenot, 2010:22). Para quienes se asumieron como «verdaderos radicales» las prácticas del gobierno radical expusieron una continuidad con un sistema pasado y repugnante. Más aún, para aquéllos los principios de la UCRSF debían instalar una frontera política e histórica.

A su vez, los esfuerzos del radicalismo oficialista por controlar el resultado no alcanzaron para imponer su candidato, pese a que ganó en votos. El hecho de que cada departamento constituya un distrito electoral y que, como ya se referenció, no todos tengan la misma representación en el caso de electores a gobernador y a diputados, hace que el partido que obtiene la mayor cantidad de votos en todo el territorio provincial no se asegure la mayoría de electores (Piazzesi y Carrizo, 2013). El escrutinio se realizó en una atmósfera de tensión donde, como hemos señalado, abundaron las denuncias, incluso ante la posibilidad de alteración del orden público el gobierno nacional ordenó la concentración en la ciudad capital de tropas y buques de guerra. ${ }^{24}$

Con 30 electores sobre 60, los disidentes debieron buscar acuerdos ya que para consagrar gobernador se necesitaba mayoría absoluta de los electores presentes, y la elección y el escrutinio debían hacerse con la presencia de las dos terceras partes del total. El 4 de marzo se reunió el colegio electoral. Luego de la validación de los diplomas, los electores realizaron una primera votación: Lehmann-Elizalde (UCRSF) 30 votos, Mosca-Mendieta (UCR), 16 y Thedy-Martínez Zuviría (PDP), 14. Luego de un cuarto intermedio, la segunda votación se 
realizó entre las fórmulas que más votos habían obtenido, produciéndose este resultado: Lehmann-Elizalde 44 votos y Mosca-Mendieta, 16, lo que significó que los electores del PDP transfirieron sus votos a la UCRSF.

\section{BALANCE DE UNA COYUNTURA FUNDACIONAL}

La condición de enunciadores legítimos que asumieron los radicales disidentes transparentó la conflictiva relación que mantuvieron la UCRSF y la UCR, resultado de las acciones desplegadas por la organización nacional en el distrito santafesino en la elección de gobernador, en la que los gubernistas fueron derrotados por los disidentes, pese a la incursión de la dirigencia de la UCR, con Yrigoyen a la cabeza. La bandera de la moralidad cívica y política enarbolada por el radicalismo había sido erosionada por la propia UCR, según la UCRSF pero al mismo tiempo, el triunfo de la fórmula disidente Rodolfo Lehmann-Francisco Elizalde rescataba los elementos identitarios. Pero no había un lazo capaz de comprometer a los electores disidentes en el acompañamiento de la fórmula Hipólito Yrigoyen-Pelagio Luna. Con esta impronta, los radicales santafesinos se presentaban en la arena nacional. Las banderas identitarias que se había esforzado por construir al calor de una inacabada aspiración a regenerar la política, no habían podido contener las facciones. O quizás, su férrea defensa había legitimado la lógica facciosa. Así fue como el colegio electoral reunido a los efectos de definir la fórmula presidencial, cobijó las complejas herencias de la primera experiencia gubernamental del radicalismo en un espacio subnacional.

La consagración de la fórmula Lehmann-Elizalde dio cuenta del triunfo de una organización partidaria - la UCRSF- que expuso su distanciamiento de la UCR, en el derrotero hacia las elecciones presidenciales. Los conflictivos vínculos entre ambas tuvieron un fuerte impacto pues brindaron la oportunidad para colocar en discusión el futuro inmediato de la UCR en el colegio electoral de 1916. El resultado es conocido: la fórmula Yrigoyen-Luna fue consagrada en el colegio electoral, no sin negociaciones y tensiones previas entre los radicalismos: la UCR con 133 electores y la UCRSF con 19, que finalmente sumaron sus electores. 
Se consagró con este resultado un hito fundacional, no sólo en la historia del radicalismo, sino también en la historia política argentina.

La historia militante del radicalismo ocluyó —al menos hasta la indisimulable división de mediados de los años veinte - el lugar de la lógica facciosa. Los «radicalismos» se encontraron en el escenario electoral disputando en forma simultánea oficialismo y oposición, generando un predominio electoral pero también una alternancia de facciones que buscaron construir sus propias organizaciones partidarias, más o menos estables o coyunturales, sin renunciar al sello, tópicos y argumentaciones con los que ocuparon el espacio público.

La facción, como forma de articulación entre los protagonistas, otorgó mayores expectativas a los actores, profundizó la disputa por los lugares de poder, otorgó a la UCR y a la UCRSF esa impronta en donde el conflicto les fue inherente. A partir de esta conclusión, cabría preguntarnos ¿Cuál es la huella que las facciones dejaron en las culturas políticas de la sociedad argentina? ¿Hasta qué punto la faccionalización no brindó las condiciones de posibilidad para la conformación de una lógica impugnadora del adversario, puesto generalmente en un campo de dudosa legitimidad aunque reconocido y de alguna manera incluido en la arena electoral? ¿Hasta dónde pervive la idea de «reparar» o «regenerar» en la prospectiva de las organizaciones políticas que recorren los escenarios electorales?

En el entramado de los múltiples combates y debates librados en este período que aquí expusimos, la interpretación que para otros escenarios propone Michel Offerlé (2011) resulta provocadora al momento de desentrañar la dinámica de la política y de lo político. En sus trabajos, el sociólogo francés coloca un fuerte acento en las prácticas y en los actores que coadyuvaron a construirlas pero también a destruirlas, en constantes movimientos de ensayo y error lo que nos sitúa, ante los grandes relatos y sus representaciones, frente a una «historia desencantada» de la democracia. 


\section{REFERENCIAS BIBLIOGRÁFICAS}

Aboy Carlés, G. (2001). Las dos fronteras de la democracia argentina. Rosario: Homo Sapiens.

(2005). Populismo y democracia en la Argentina contemporánea. Entre el hegemonismo y la refundación. Estudios Sociales, 28, 125-149.

Angenot, M. (2010). El discurso social. Los límites históricos de lo pensable y lo decible. Buenos Aires: Siglo XXI.

Ansaldi, W. (2000). La trunca transición del régimen oligárquico al régimen democrático. En Falcón, R. (Dir.) Democracia, conflicto social y renovación de ideas (19161930) (15-57). Buenos Aires: Sudamericana.

Berstein, S. (1999). La cultura política. En Jean-Pierre Rioux y Jean-François Sirinelli (Dir.) Para una historia cultural (389-405). México: Taurus.

Botana, N. ([1985] 2012). El orden conservador. La política argentina entre 1880 y 1916. Buenos Aires: Edhasa.

— (1988). La tradición política en la Argentina moderna. En Pinto, J. (Comp.) Ensayos sobre la crisis política argentina páginas, T. II, (105-122). Buenos Aires: CEAL. Cabrera, M.A. (2010). La investigación histórica y el concepto de cultura política. En Pérez Ledesma, M. y Sierra, M. (eds.) Culturas políticas: teoría e historia (19-85). Zaragoza: Institución «Fernando el Católico» (CSIC).

Carrizo, B. (2013). ¿Gobernar con el enemigo? Los radicales santafesinos en los inicios de la democracia electoral. Santa Fe, 1912-1916. Cuadernos del Ciesal, 12, 101-125. Recuperado https://rephip.unr.edu.ar/bitstream/handle/2133/5939/06Carrizo.pdf? sequence $=3$ \&isAllowed $=y$ (fecha de consulta: 18/02/2017)

- (2014). Partidos políticos, campañas electorales y comicios en un momento fundacional: el triunfo de la Unión Cívica Radical de Santa Fe (1912). Papeles del Centro de Investigaciones, 15, 81-102.

- (2017). Tirios y troyanos navegan en el regeneracionismo. Los conflictos del radicalismo en la construcción de la democracia electoral (Santa Fe, 1912-1920). En Bacolla, N., Donatello, L. y Carrizo, B. (2017). Política, sociedad, instituciones y saberes. Diálogos interdisciplinares e intercontinentales (205-239). Santa Fe: ediciones UNL.

Castro, M. (2012). El ocaso de la república oligárquica. Buenos Aires: Edhasa. 
de Diego Romero, J. (2006). El concepto de «cultura política» en ciencia política y sus implicaciones para la historia, Ayer. Revista de Historia Contemporánea, 61. Recuperado de http://www.ahistcon.org/PDF/numeros/ayer61_RepresentacionPoliticaEspanaLiberal_Sierra_Zurita_Pena.pdf (fecha de consulta: 22/02/2017)

de Privitellio, L. (2004). Partidos políticos. En Korn, F. y de Asua, M. (comp.) Investigación Social. Errores eruditos y otras consideraciones (1-8). Buenos Aires: Academia Nacional de Ciencias de Buenos Aires. Recuperado de http://www.unsam.edu. ar/escuelas/politica/centro_historia_politica/material/partidos_pollticos.pdf (fecha de consulta: 15/04/2016)

del Mazo, G. (1955). Breve historia de la Reparación Nacional. En Comité de la Juventud «Dr. Luis Dellepiane» Definiciones radicales (27-65). La Plata: UCR.

- (1957). El radicalismo. Ensayo sobre su historia y doctrina, T. I. Buenos Aires: Gure.

Di Meglio, G. (2008). Patria. En Goldman, N. (ed.), Leguaje y revolución. Conceptos políticos clave en el Río de la Plata, 1780-1850 (115-130). Buenos Aires: Prometeo.

Macor, D. e Iglesias, E. (1997). El peronismo antes del peronismo. Memoria e historia en los orígenes del peronismo santafesino. Santa Fe, ediciones UNL.

Macor, D. (1998). Competitividad interpartidaria y sociabilidad política, Santa Fe, 1930-1943. Estudios Sociales, 14, 105-127.

Morán, M.L. (2010). Cultura y política: nuevas tendencias en los análisis sociopolíticos. En Pérez Ledesma, M. y Sierra, M. (eds.) Culturas políticas: teoría e historia (87-131). Zaragoza: Institución «Fernando el Católico» (CSIC).

Offerlé, M. (2011). Perímetros de lo político: contribuciones a una socio-historia de la política. Buenos Aires: Antropofagia.

Palti, E. (2005). Temporalidad y refutabilidad de los conceptos políticos. Prismas, 9, 19-34. Recuperado de https://www.redalyc.org/articulo.oa?id=387036777002 (fecha de consulta: 10/02/2018)

- (2007). El tiempo de la política. El siglo XIX reconsiderado Buenos Aires: Siglo XXI.

Panebianco, A. (2000). Modelos de partido. Organización y poder en los partidos políticos Madrid: Alianza. 
Persello, A.V. (2004). El partido radical. Gobierno y oposición (1916-1943). Buenos Aires: Siglo XXI.

- (2007). Historia del radicalismo. Buenos Aires: Edhasa.

Persello, A.V. y de Privitellio, L. (2009). La Reforma y las reformas: la cuestión electoral en el Congreso (1912-1930). En Bertoni, L. y de Privitellio, L. Conflictos en democracia. La vida política argentina entre dos siglos (89-121), Buenos Aires: Siglo XXI.

Romero, J.L. (1998). El desarrollo de las ideas en la sociedad argentina del siglo XX, Buenos Aires: A-Z editora.

Piazzesi, S. y Carrizo, B. (2013). Instituciones y prácticas políticas en la hora de la democracia electoral. Santa Fe, 1916-1920. Revista de Historia, 14. Recuperado de http://revele.uncoma.edu.ar/htdoc/revele/index.php/historia/article/view/549/539 (fecha de consulta: 01/02/2018)

Rosanvallon, P. (2003). Por una historia conceptual de lo político, Fondo de Cultura Económica, Buenos Aires.

Salavert Fabiani, V. y Suárez Cortina, M. (ed) (2007). El regeneracionismo en España. Política, educación, ciencia y sociedad, Valencia: Universitat de València.

Terán, O. (2008). Vida intelectual en el Buenos Aires fin-de-siglo (1880-1910). Derivas de la «cultura científica». Buenos Aires: FCE. 